\title{
Pulmonary artery interventions after Norwood procedure: Does type or position of shunt predict need for intervention?
}

\author{
Katja M. Gist, DO, MSCS, ${ }^{a}$ Cindy S. Barrett, MD, MPH, ${ }^{a}$ Dionne A. Graham, PhD, ${ }^{b}$ \\ Sheri L. Crumback, RDCS, ${ }^{a}$ Eleanor L. Schuchardt, MD, ${ }^{a}$ Brian Erickson, MD, ${ }^{c}$ and James Jaggers, MD $^{\mathrm{c}}$
}

Objectives: Pulmonary artery stenosis is a potential complication after Norwood palliation for hypoplastic left heart syndrome. It is unclear whether the shunt type or position in the Norwood procedure is associated with the risk of the development of pulmonary artery stenosis. We examined the risk of pulmonary artery stenosis and the need for pulmonary artery intervention in children undergoing the Norwood procedure with either the right ventricle to pulmonary artery conduit or modified Blalock-Taussig shunt.

Methods: A retrospective review was performed of all patients who underwent the Norwood procedure from January 1, 2003, to September 1, 2011. The data from 100 patients were reviewed, including catheterization and echocardiographic data, right ventricle to pulmonary artery conduit $(\mathrm{n}=67$, right shunt position in 17 and left in 50), and right ventricle to pulmonary artery $(\mathrm{n}=33)$. The primary outcome measure was the need for operative or catheter-based pulmonary artery intervention.

Results: No patients in the right ventricle to pulmonary artery group required catheterization-based pulmonary artery interventions. Surgical pulmonary arterioplasty was performed frequently and equally in both the right ventricle to pulmonary artery and right ventricle to pulmonary artery groups at the bidirectional Glenn procedure. Catheter-based pulmonary arterioplasty was performed more frequently in the right ventricle to pulmonary artery conduit group, especially when the conduit was positioned to the right side of the neoaorta. These patients had a 12.73 increased odds of a pulmonary artery intervention compared with the left to right ventricle to pulmonary artery conduit $(P=.04)$.

Conclusions: Consistent with a previous multicenter randomized trial, patients who received a right ventricle to pulmonary artery conduit versus a right ventricle to pulmonary artery have a greater risk of requiring pulmonary artery interventions. Patients with right ventricle to pulmonary artery conduit placement to the right underwent a greater number of pulmonary artery interventions but demonstrated overall improved growth of the branch pulmonary arteries compared with the patients receiving a left-sided right ventricle to pulmonary artery conduit.

(J Thorac Cardiovasc Surg 2013;145:1485-92)

Earn CME credits at

http://cme.ctsnetjournals.org

Surgical intervention of hypoplastic left heart syndrome (HLHS) and dominant right ventricle variants consists of a 3-staged palliation, including the Norwood procedure (NP), bidirectional Glenn (BDG) procedure, and Fontan procedure. In the NP, provision of pulmonary blood flow

\footnotetext{
From the Department of Pediatrics, ${ }^{\text {a }}$ Heart Institute, Children's Hospital Colorado, Aurora, Colo; Department of Cardiology, ${ }^{\mathrm{b}}$ Children's Hospital Boston, and Department of Pediatrics, Harvard Medical School, Boston, Mass; and Department of Surgery, ${ }^{\mathrm{c}}$ Pediatric Cardiac Surgery, Children's Hospital Colorado, Aurora, Colo. Disclosures: Authors have nothing to disclose with regard to commercial support. Read at the 38th Annual Meeting of The Western Thoracic Surgical Association, Maui, Hawaii, June 27-30, 2012.

Received for publication May 11, 2012; revisions received Nov 19, 2012; accepted for publication Jan 11, 2013; available ahead of print Feb 11, 2013.

Address for reprints: Katja M. Gist, DO, MSCS, Department of Pediatrics, Heart Institute, Children's Hospital Colorado, 13123 E 16th Ave, B100, Aurora, CO 80045 (E-mail: gist.kat@gmail.com).

0022-5223/\$36.00

Copyright (c) 2013 by The American Association for Thoracic Surgery

http://dx.doi.org/10.1016/j.jtcvs.2013.01.014
}

is accomplished with either a modified Blalock-Taussig shunt (mBTS) or a right ventricle to pulmonary artery (RV-PA) conduit.

Successful palliation is dependent on the optimal growth and development of the pulmonary vasculature. The shunt type and position might be associated with differences in pulmonary artery (PA) growth and the potential need for PA intervention. ${ }^{1-5}$ Controversy exists over which shunt type and the relative position (right or left of the neoaorta) is associated with the development of important PA stenosis and the best PA growth. ${ }^{1,2,5-10}$

The purposes of the present study were (1) to determine whether the shunt type (mBTS vs RV-PA conduit) was associated with the need for catheter-based PA intervention and (2) to determine whether the position of the RV-PA conduit to the left or right side of the neoaorta was associated with the need for catheter-based PA intervention.

\section{METHODS}

All patients who underwent the NP from January 2003 to September 2011 were included in the present study. None of the patients underwent a hybrid procedure. The patient cohort was divided according to the shunt type used: the RV-PA conduit in 67 and the mBTS in 33. The RV-PA 


$$
\begin{aligned}
& \text { Abbreviations and Acronyms } \\
& \text { BDG }=\text { bidirectional Glenn } \\
& \text { CI }=\text { confidence interval } \\
& \text { HLHS }=\text { hypoplastic left heart syndrome } \\
& \mathrm{mBTS}=\text { modified Blalock-Taussig shunt } \\
& \text { NP }=\text { Norwood procedure } \\
& \text { PA }=\text { pulmonary artery } \\
& \text { RV-PA }=\text { right ventricle to pulmonary artery } \\
& \text { Qp/Qs }=\text { pulmonary/systemic blood flow }
\end{aligned}
$$

conduit cohort was further stratified into 2 groups according to the conduit position in relationship to the neoaorta: left in 50 and right in 17. The primary outcomes included the need for operative or catheter-based PA intervention, operative and interstage mortality, and the need for cardiac transplantation before the Fontan procedure. Operative mortality was defined as death occurring in the hospital or within 30 days of surgery ${ }^{11}$ and was divided into 2 eras, early (2003-2008) and late (2009-2011). The University of Colorado institutional review board approved the present study.

Echocardiograms were evaluated before the NP and BDG procedure. If a patient required PA intervention, the echocardiogram preceding any intervention was used (all follow-up echocardiograms are referred to as preBDG echocardiograms). Right ventricular function, tricuspid valve function, and PA measurements were evaluated by echocardiography before the NP and BDG procedure. A single cardiac sonographer who was unaware of the operative or catheter-based PA interventions reviewed all echocardiograms.

Tricuspid valve regurgitation was graded using the color Doppler patterns in accordance with the American Society of Echocardiography and graded on a scale of 0 to 6 ( 0 , none; 1 , trivial; 2 , mild; 3 , mild to moderate; 4 , moderate; 5 , moderate to severe; and 6 , severe). ${ }^{12}$ Right ventricular function was recorded as normal, mildly reduced, moderately reduced, or severely reduced. The branch PA dimensions were measured from the parasternal or suprasternal short-axis views at the hilum of the vessel (before the first branching point). If the images were suboptimal for measurement, the data were excluded. PA growth was evaluated by echocardiography. A change in PA size was determined for noninvasive evaluation of PA growth after controlling for weight and the number of days between the echocardiograms.

The angiograms were reviewed, and the PA dimensions were measured off-line using an empty catheter of known size for calibration. The dimension of the descending thoracic aorta was determined at the level of the diaphragm using the same calibration technique. The right and left PA size, McGoon index, and Nakata index were determined from the pre-BDG catheterization procedure. ${ }^{13,14}$ The total number of catheter procedures and interventions were determined for each stage. The angiographic measurements were made before an intervention on the PAs.

\section{Statistical Analysis \\ The data were collected using Research Electronic Data Capture. ${ }^{15}$ The data were analyzed using SPSS (SPSS, version 12, for Windows, release 12.0.7; SPSS, Chicago, Ill). The categorical variables were compared using the chi-square test or Fisher's exact test. Continuous variables are reported as the mean \pm standard deviation and were compared using I tests. Logistic regression analysis was used to determine the association between the shunt position and the need for PA intervention.}

\section{RESULTS}

\section{Comparison of mBTS and RV-PA Conduit}

The patient demographics and operative characteristics for the comparison of shunt type are listed in Table 1 .
Patients undergoing an NP palliated with an mBTS showed a trend toward longer cardiopulmonary bypass, circulatory arrest, and crossclamp times.

The operative mortality after the NP was 3 of $18(17 \%$; $95 \%$ confidence interval $[\mathrm{CI}], 4 \%-41 \%$ ) for the mBTS, and 12 of $48(25 \% ; 95 \% \mathrm{CI}, 13 \%-37 \%)$ for the RV-PA conduit in the early era (2003-2008). In contrast, the operative mortality for the recent era (2009-2011) was 2 of 15 $(13 \% ; 95 \%$ CI, $2 \%-40 \%)$ for the mBTS and 1 of 19 $(5 \%$; $95 \%$ CI, $0 \%-26 \%)$ for the RV-PA conduit. No significant difference was seen in the overall operative mortality or operative mortality between the shunt types during the early or recent era. In the early era, 14 patients $(21 \%)$ required extracorporeal membrane oxygenation after the NP compared with 1 patient $(3 \%)$ in the recent era $(P=.02)$. Of the patients who required extracorporeal membrane oxygenation, $11(73 \%)$ did not survive to hospital discharge (Figure 1). Two patients required transplantation after the $\mathrm{NP}(\mathrm{mBTS}, \mathrm{n}=1$; RV-PA conduit, $\mathrm{n}=1)$.

The demographics and surgical characteristics at the BDG procedure are listed in Table 1. In those who underwent initial palliation with an mBTS, 9 of 21 (43\%) underwent surgical PA patch plasty (bilateral, $\mathrm{n}=4$; left, $\mathrm{n}=2$; right, $\mathrm{n}=3$ ) at the BDG procedure. In those palliated with the RV-PA conduit, 22 of $44(50 \%)$ underwent surgical patch plasty of the PAs (bilateral, $\mathrm{n}=16$; left, $\mathrm{n}=2$; right, $\mathrm{n}=4$ ) at the BDG procedure. No difference was seen in the need for surgical pulmonary arterioplasty between the shunt types $(P=.6)$. The operative mortality after the BDG procedure was 2 of $64(3 \%)$ (mBTS, 1/21; RV-PA conduit, $1 / 44)$. Three interstage deaths occurred after the BDG procedure (mBTS, $\mathrm{n}=1$; RV-PA conduit, $\mathrm{n}=2$ ). Two patients underwent transplantation after the BDG procedure (both palliated with an RV-PA conduit). No operative mortality occurred after the Fontan procedure. Three patients underwent heart transplantation after the Fontan procedure (mBTS, $\mathrm{n}=1$; RV-PA conduit, $\mathrm{n}=2$ ).

Overall, 63 patients required at least 1 catheterization between the NP and BDG procedure (Table 2). Of the 28 procedures performed in 20 patients palliated with an mBTS, no interventions were performed. Eight patients did undergo 2 catheterization procedures each. In the RV-PA conduit group, 52 procedures were performed in 43 patients. The indications, location, and interventions performed are listed in Table 3. Four patients underwent angioplasty once and two underwent angioplasty at 2 separate catheterizations.

The cardiac catheterization data are listed in Table 2. A significantly greater pulmonary/systemic blood flow $(\mathrm{Qp} / \mathrm{Qs})$ ratio was found in those palliated with an $\mathrm{mBTS}$ than in those palliated with an RV-PA conduit $(P=.03)$.

After the BDG procedure, 48 cardiac catheterization procedures were performed for both groups. In the mBTS group, 8 patients underwent 10 catheterization procedures 
TABLE 1. Demographics and operative characteristics for Norwood and bidirectional Glenn procedure for modified Blalock-Taussig shunt and right ventricle to pulmonary artery conduit

\begin{tabular}{|c|c|c|c|c|c|}
\hline \multirow[b]{2}{*}{ Variable } & \multicolumn{2}{|c|}{ mBTS } & \multicolumn{2}{|c|}{ RV-PA } & \multirow[b]{2}{*}{$P$ value } \\
\hline & Patients (n) & Value & Patients (n) & Value & \\
\hline \multicolumn{6}{|l|}{ NP } \\
\hline Patients & 33 & & 67 & & \\
\hline Age at surgery (d) & 33 & $6.8 \pm 3.4$ & 67 & $7.5 \pm 5.1(4,10)$ & .38 \\
\hline Male $(\%)$ & 33 & $20(61 \%)$ & 67 & $37(55 \%)$ & .67 \\
\hline Weight $(\mathrm{kg})$ & 33 & $3.1 \pm 0.4$ & 67 & $3.1 \pm 0.5$ & .64 \\
\hline Gestational age (wk) & 33 & $38.7 \pm 1.3$ & 67 & $38.3 \pm 1.5$ & .10 \\
\hline CPB time (min) & 33 & $188.5 \pm 42.5$ & 67 & $172.7 \pm 43.8$ & .09 \\
\hline Circulatory arrest time (min) & 33 & $19 \pm 21.1$ & 66 & $14.2 \pm 22.5$ & .25 \\
\hline Crossclamp $(\mathrm{min})$ & 33 & $60.4 \pm 24.6$ & 66 & $51 \pm 21$ & .07 \\
\hline $\mathrm{SpO}_{2}$ at discharge & 28 & $78 \pm 4$ & 49 & $79 \pm 6$ & .94 \\
\hline \multicolumn{6}{|l|}{$\mathrm{BDG}$ procedure } \\
\hline Patients & 21 & & 44 & & \\
\hline Age (mo) & 21 & $6 \pm 2.4$ & 44 & $5.2 \pm 1.7$ & .17 \\
\hline Weight $(\mathrm{kg})$ & 21 & $6.3 \pm 1.4$ & 44 & $5.7(5,7.01)$ & .09 \\
\hline CPB time (min) & 20 & $109.6 \pm 57.7$ & 44 & $97 \pm 44.9$ & .39 \\
\hline Circulatory arrest time (min) & 20 & $13 \pm 23.1$ & 44 & $13.4 \pm 25.3$ & .95 \\
\hline Crossclamp (min) & 20 & $13.4 \pm 14.9$ & 44 & $4.4 \pm 11$ & .02 \\
\hline Surgical PA intervention & 21 & $9(43 \%)$ & 44 & $22(50 \%)$ & .61 \\
\hline
\end{tabular}

$\overline{m B T S}$, Modified Blalock-Taussig shunt; $R V$ - $P A$, right ventricle to pulmonary artery conduit; $N P$, Norwood procedure; $C P B$, cardiopulmonary bypass; $S p O_{2}$, oxygen saturation; $P A$, pulmonary artery.

with no PA interventions ( 2 patients underwent 2 catheterization procedures). In the RV-PA conduit group, 25 patients underwent 38 catheterization procedures ( 9 patients underwent 2 catheterizations and 2 patients underwent 3 catheterizations). The indications, location, and interventions performed are listed in Table 3. Five patients underwent 2 catheterization procedures, and two underwent 3 catheterization procedures each. Eight patients underwent angioplasty once, and two each underwent angioplasty at 2 different catheterizations.

The PA echocardiographic dimensions before the NP and BDG procedure for shunt type are listed in Table 2 .

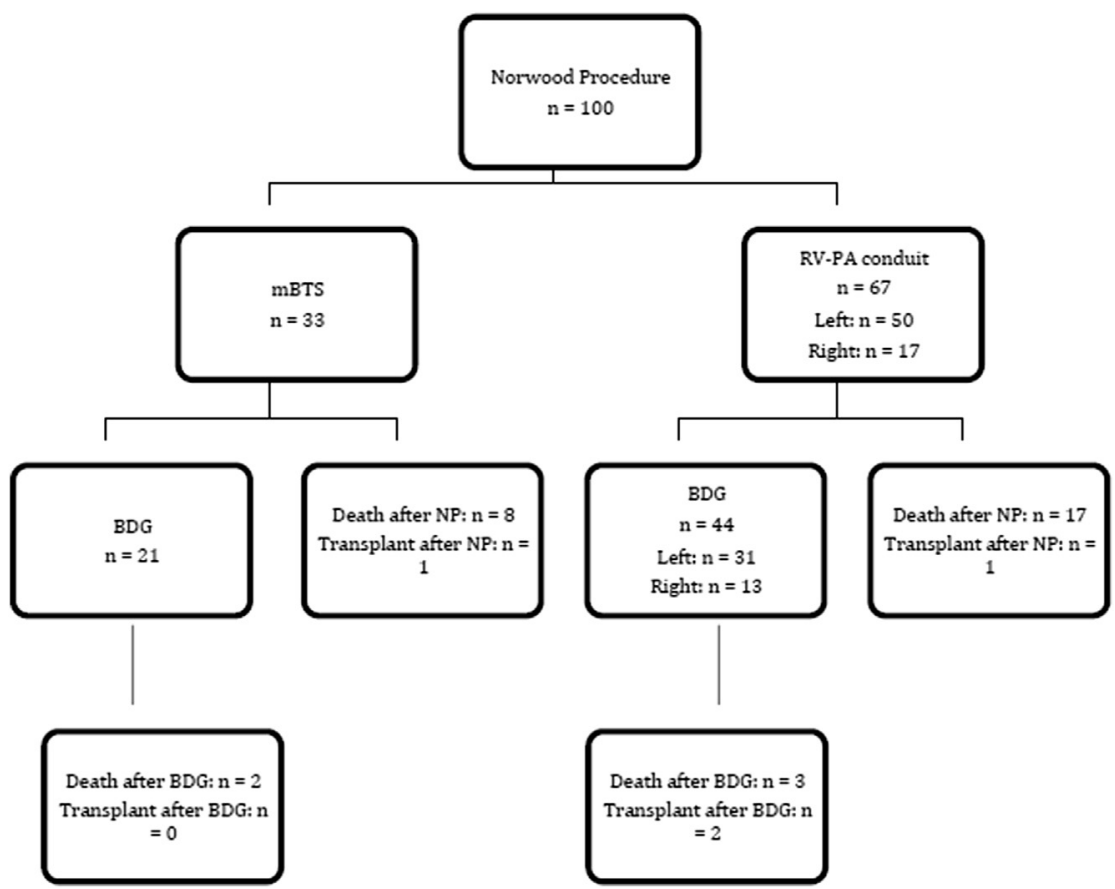

FIGURE 1. Flow chart demonstrating distribution of patients by procedure and type of shunt, including overall mortality. $m B T S$, Modified Blalock-Taussig shunt; $R V-P A$, right ventricle to pulmonary artery; $B D G$, bidirectional Glenn (procedure); $N P$, Norwood procedure. 
TABLE 2. Cardiac catheterization and echocardiographic data for comparison of modified Blalock-Taussig shunt and right ventricle to pulmonary artery conduit

\begin{tabular}{|c|c|c|c|c|c|}
\hline \multirow[b]{2}{*}{ Variable } & \multicolumn{2}{|c|}{ mBTS } & \multicolumn{2}{|c|}{ RV-PA conduit } & \multirow[b]{2}{*}{$P$ valu } \\
\hline & Patients (n) & Value & Patients (n) & Value & \\
\hline \multicolumn{6}{|l|}{ Pre-BDG hemodynamics and measurements } \\
\hline Patients & 20 & & 38 & & \\
\hline McGoon ratio & 19 & $1.4 \pm 0.6$ & 35 & $1.5 \pm 0.6$ & .63 \\
\hline Nakata index & 20 & $269.6 \pm 223.5$ & 36 & $264.7 \pm 142.3$ & .93 \\
\hline Qp/Qs at pre-BDG catheterization & 20 & $1.3 \pm 0.6$ & 38 & $0.9 \pm 0.3$ & .03 \\
\hline Interstage 1 , catheter PA intervention* & 20 & $0 / 28$ & 43 & $8 / 52$ & .05 \\
\hline Interstage 2, catheter PA intervention* & 8 & $0 / 16$ & 25 & $12 / 38$ & .01 \\
\hline \multicolumn{6}{|c|}{ Echocardiogram measurements of PA dimension } \\
\hline Patients & 19 & & 41 & & \\
\hline RPA (mm) before NP & 19 & $4.6 \pm 0.7$ & 41 & $4.5 \pm 0.7$ & .94 \\
\hline RPA (mm) before BDG & 12 & $4.1 \pm 1.1$ & 32 & $4.2 \pm 1.1$ & .76 \\
\hline Change in RPA dimension & 11 & $-0.5 \pm 1.4$ & 29 & $-0.4 \pm 1.2$ & .78 \\
\hline LPA $(\mathrm{mm})$ before NP & 19 & $4.3 \pm 0.9$ & 40 & $4.6 \pm 0.7$ & .26 \\
\hline LPA (mm) before BDG & 13 & $4.3 \pm 1.4$ & 31 & $4.3 \pm 1.2$ & .99 \\
\hline Change in LPA dimension & 12 & $0.3 \pm 1.5$ & 27 & $-0.3 \pm 1.6$ & .27 \\
\hline
\end{tabular}

mBTS, Modified Blalock-Taussig shunt; $R V-P A$, right ventricle to pulmonary artery conduit; $B D G$, bidirectional Glenn (procedure); $Q p$, pulmonary blood flow; $Q s$, systemic blood flow; $P A$, pulmonary artery; $R P A$, right PA; $L P A$, left PA; $N P$, Norwood procedure. *Number of patients and ratio represents number of interventions/number of catheterization procedures.

No significant differences were found in the baseline PA dimensions or interstage 1 PA growth between shunt types.

Right ventricular function was assessed at baseline and before the BDG procedure. No significant difference was found in ventricular function between those palliated with an mBTS and an RV-PA conduit at the baseline echocardiogram $(P=.67)$ or before the BDG procedure. The median interval to the follow-up (before BDG) echocardiogram was 136 days (interquartile range, 112-217 days).

TABLE 3. Indications, type, and location of intervention in patients palliated with right ventricle to pulmonary artery conduit when positioned to left or right of neoaorta

\begin{tabular}{|c|c|c|c|c|c|c|}
\hline Conduit position & Patients (n) & $\begin{array}{c}\text { Catheterization } \\
\text { procedure (n) }\end{array}$ & $\begin{array}{l}\text { Indication for } \\
\text { catheterization }\end{array}$ & Intervention (n) & $\begin{array}{c}\text { Intervention } \\
\text { location }\end{array}$ & $P$ value \\
\hline Interstage- $1^{*}$ & & & & & & .09 \\
\hline \multirow[t]{6}{*}{ Left } & 29 & 36 & Hypoxia in 2 & 3 & Left in 1 & \\
\hline & & & Decreased function in 1 & & Bilateral in 2 & \\
\hline & & & Respiratory failure in 1 & & & \\
\hline & & & Arch obstruction in 5 & & & \\
\hline & & & PA hypoplasia in 1 & & & \\
\hline & & & Diagnostic in 26 & & & \\
\hline \multirow[t]{4}{*}{ Right } & 14 & 16 & Hypoxia in 3 & 5 & Left in 1 & \\
\hline & & & Decreased function in 1 & & Right in 1 & \\
\hline & & & PA hypoplasia in 2 & & Bilateral in 3 & \\
\hline & & & Diagnostic in 10 & & & \\
\hline Interstage $-2 \dagger$ & & & & & & .008 \\
\hline \multirow[t]{5}{*}{ Left } & 21 & 31 & Hypoxia in 3 & 7 & Left in 7 & \\
\hline & & & Arch obstruction in 1 & & & \\
\hline & & & PA hypoplasia in 9 & & & \\
\hline & & & Diagnostic in 13 & & & \\
\hline & & & Otherț in 4 & & & \\
\hline \multirow[t]{3}{*}{ Right } & 4 & 6 & Decreased function in 1 & 5 & Left in 1 & \\
\hline & & & PA hypoplasia in 5 & & Right in 2 & \\
\hline & & & & & Bilateral in 2 & \\
\hline
\end{tabular}

All patients underwent angioplasty only. PA, Pulmonary artery. ${ }^{*}$ In left RV-PA group, 3 patients underwent 2 catheterizations and 2 underwent 3 catheterizations, with 3 total interventions; 1 patient underwent 2 PA interventions; in right RV-PA group, 2 patients underwent 2 catheterization procedures, with 5 total interventions; 1 patient underwent 2 interventions. $\dagger$ In left RV-PA group, 7 patients underwent 2 catheterization procedures, and 2 underwent 3 catheterization procedures; 7 interventions were performed in 7 patients; in right RV-PA group, 2 patients underwent 2 catheterization procedures; 2 patients underwent 2 interventions each. $\ddagger$ Persistent chylothorax in 1 , neoaortic valve obstruction in 1 , and superior vena cava obstruction in 3 . 
Tricuspid valve regurgitation at the pre-BDG echocardiogram in the mBTS group was as follows: none in 3, trivial in 7 , mild in 5, and moderately severe in 1 . Tricuspid valve regurgitation in the RV-PA conduit group was as follows: none in 1 , trivial in 19 , mild in 11 , mild to moderate in 3 , moderate in 4 , and severe in 1 . No significant difference was found in the incidence of tricuspid valve regurgitation between the 2 groups $(P=.39)$.

\section{Comparison Between Left and Right RV-PA Conduit Position}

The patient demographics and operative characteristics for the comparison of shunt position are listed in Table 3. The patients in the right RV-PA conduit group were younger at the NP $(P<.001)$. The oxygen saturation at discharge from the NP was significantly greater $(83 \%)$ in the right RV-PA group than in the left RV-PA group $(78 \%$; $P=.001)$. The difference was not clinically significant.

In the left-sided group $(\mathrm{n}=50), 3$ different shunt sizes were used: $4 \mathrm{~mm}$ in $7,5 \mathrm{~mm}$ in 40 , and $6 \mathrm{~mm}$ in 3 . In the right-sided group $(\mathrm{n}=17), 2$ different shunt sizes were used: $5 \mathrm{~mm}$ in 2 and $6 \mathrm{~mm}$ in 15. A significant difference was present in the shunt size between the left and right groups $(P<.0001)$. The mean oxygen saturation at the NP in those palliated with a $5-\mathrm{mm}$ shunt was significantly lower $(78 \% \pm 6 \%)$ than that in those palliated with a 6 -mm shunt $(82 \% \pm 4 \% ; P=.01)$. Despite this difference in oxygen saturation between shunt sizes, no difference was found in the number of patients requiring oxygen at discharge (5-mm shunt, $11 / 31$ [35\%] vs 6-mm shunt, 5/16 $[31 \%] ; P=.52)$. The right PA dimensions were not different in patients palliated with a $5-\mathrm{mm}$ or 6-mm shunt before the NP or BDG procedure (NP $5 \mathrm{~mm}, 4.5 \pm 0.9 \mathrm{~mm}$ vs NP $6 \mathrm{~mm}, 4.4 \pm 0.7 \mathrm{~mm}, P=.26$; BDG procedure $5 \mathrm{~mm}, 4.1 \pm$ $1 \mathrm{~mm}$ vs BDG procedure $6 \mathrm{~mm}, 4.4 \pm 0.9 \mathrm{~mm} ; P=.37$ ). The left PA dimensions were not different in patients palliated with a 5-mm or 6-mm shunt before the NP or BDG procedure (NP $5 \mathrm{~mm}, 4.6 \pm 0.8 \mathrm{~mm}$ vs NP $6 \mathrm{~mm}$, $4.4 \pm 0.7 \mathrm{~mm}, P=.22$; BDG procedure $5 \mathrm{~mm}, 4.3 \pm$ $1.4 \mathrm{~mm}$ vs BDG procedure $6 \mathrm{~mm}, 4.5 \pm 1 \mathrm{~mm}, P=.4$ ).

The operative mortality for the left RV-PA conduit position was $13(26 \% ; 95 \% \mathrm{CI}, 14 \%-38 \%)$ and $1(6 \% ; 95 \%$ CI, $1 \%-29 \%$ ) for the right RV-PA conduit position $(P=.09)$. One patient with the RV-PA conduit to the left side of the neoaorta died after the BDG procedure. All the patients who underwent transplantation were those with the RV-PA conduit to the left side of the neoaorta. None of those with the RV-PA conduit to the right side of the neoaorta were old enough at the last follow-up visit to be considered for the Fontan procedure.

The patients with the RV-PA conduit to the right side of the neoaorta required surgical pulmonary arterioplasty at the BDG procedure more frequently than did the left RV-PA group $(P=.05$; Table 3$)$. Twelve patients palliated
TABLE 4. Demographics and operative characteristics for Norwood and bidirectional Glenn procedures stratified by right ventricle to pulmonary artery conduit position

\begin{tabular}{|c|c|c|c|c|c|}
\hline \multirow[b]{3}{*}{ Variable } & \multicolumn{4}{|c|}{ RV-PA conduit position } & \multirow[b]{3}{*}{$\begin{array}{c}P \\
\text { value }\end{array}$} \\
\hline & \multicolumn{2}{|r|}{ Left } & \multicolumn{2}{|c|}{ Right } & \\
\hline & $\begin{array}{l}\text { Patients } \\
\text { (n) }\end{array}$ & Value & $\begin{array}{l}\text { Patients } \\
\text { (n) }\end{array}$ & Value & \\
\hline \multicolumn{6}{|l|}{ NP } \\
\hline Patients (n) & 50 & & 17 & & \\
\hline Age at surgery (d) & 50 & $8.4 \pm 5.5$ & 17 & $4.8 \pm 2.3$ & $<.001$ \\
\hline Males (n) & 50 & $24(48 \%)$ & 17 & $13(77 \%)$ & .05 \\
\hline Weight (kg) & 50 & $3.1 \pm 0.5$ & 17 & $3.2 \pm 0.6$ & .70 \\
\hline $\begin{array}{l}\text { Gestational age } \\
\text { (wk) }\end{array}$ & 50 & $38.3 \pm 1.4$ & 17 & $38.2 \pm 1.8$ & .83 \\
\hline CPB time (min) & 50 & $176.8 \pm 46.3$ & 17 & $160.6 \pm 33.7$ & .13 \\
\hline $\begin{array}{l}\text { Circulatory arrest } \\
\text { time (min) }\end{array}$ & 49 & $13.9 \pm 23.9$ & 17 & $14.9 \pm 18.7$ & .85 \\
\hline Crossclamp (min) & 49 & $47 \pm 21.1$ & 17 & $62.4 \pm 16.3$ & .004 \\
\hline $\mathrm{SpO}_{2}$ at discharge & 33 & $78 \pm 6$ & 16 & $83 \pm 4$ & .001 \\
\hline \multicolumn{6}{|l|}{ BDG procedure } \\
\hline Patients & 31 & & 13 & & \\
\hline Age (mo) & 31 & $5.4 \pm 1.9$ & 13 & $4.6 \pm 1.2$ & .09 \\
\hline Weight $(\mathrm{kg})$ & 31 & $5.8 \pm 1.3$ & 13 & $5.6 \pm 0.8$ & .59 \\
\hline CPB time (min) & 31 & $91.6 \pm 45.6$ & 13 & $109.7 \pm 42.3$ & .22 \\
\hline $\begin{array}{l}\text { Circulatory arrest } \\
\text { time (min) }\end{array}$ & 31 & $5.4 \pm 12.3$ & 13 & $2 \pm 7.2$ & .27 \\
\hline Crossclamp (min) & 31 & $13.7 \pm 27.5$ & 13 & $12.6 \pm 20.2$ & .89 \\
\hline $\begin{array}{l}\text { Surgical PA } \\
\text { intervention }\end{array}$ & 31 & $12(39 \%)$ & 13 & $10(77 \%)$ & .05 \\
\hline
\end{tabular}

$R V$ - $P A$, Right ventricle to pulmonary artery conduit; $N P$, Norwood procedure $C P B$, cardiopulmonary bypass; $\mathrm{SpO}_{2}$, oxygen saturation; $P A$, pulmonary artery; $B D G$, bidirectional Glenn (procedure).

with a left RV-PA conduit underwent surgical patch plasty (bilateral, $\mathrm{n}=6$; left, $\mathrm{n}=2$; right, $\mathrm{n}=4$ ) compared with 10 patients palliated with a right RV-PA conduit (bilateral, $\mathrm{n}=10)$ at the BDG procedure $(P=.05$; Table 4$)$.

The cardiac catheterization and echocardiographic data stratified by the shunt position are listed in Table 5 . The indications, location, and interventions performed for the interstage 1 and interstage 2 period for differences in shunt position are listed in Table 3.

A simple logistic regression model demonstrated that a patient with a right RV-PA conduit had a 12.73 times greater odds of having at least 1 intervention than those with a left-sided RV-PA conduit $(P=.04)$. A summary of the PA interventions is presented in Table 5.

The PA dimensions before the NP and BDG procedure stratified by the shunt position are listed in Table 5. On the pre-NP echocardiogram, the right and left PAs were significantly larger in the left RV-PA group $(P=.01$ and $P=.04$ respectively). No differences in the left PA and right PA dimensions were seen on the follow-up echocardiogram.

On the baseline echocardiogram, the function in the left RV-PA group was normal in 14 patients, moderately 
TABLE 5. Cardiac catheterization and echocardiographic data stratified by right ventricle to pulmonary artery conduit position

\begin{tabular}{|c|c|c|c|c|c|}
\hline \multirow[b]{2}{*}{ Variable } & \multicolumn{2}{|c|}{ Left RV-PA conduit } & \multicolumn{2}{|c|}{ Right RV-PA conduit } & \multirow[b]{2}{*}{$P$ value } \\
\hline & Patients (n) & Value & Patients (n) & Value & \\
\hline \multicolumn{6}{|c|}{ Pre-BDG catheterization hemodynamics and measurements } \\
\hline Patients & 25 & & 13 & & \\
\hline McGoon ratio & 24 & $1.5 \pm 0.6$ & 11 & $1.6 \pm 0.5$ & .43 \\
\hline Nakata index & 24 & $255.7 \pm 106.3$ & 12 & $282.7 \pm 200.7$ & 67 \\
\hline Qp/Qs at pre-BDG catheterization & 25 & $0.9 \pm 0.3$ & 13 & $1 \pm 0.3$ & .27 \\
\hline Interstage 1 , catheter PA intervention* & 29 & $3 / 36$ & 14 & $5 / 16$ & .09 \\
\hline Interstage 2 , catheter PA intervention* & 21 & $7 / 32$ & 4 & $5 / 6$ & .008 \\
\hline \multicolumn{6}{|c|}{ Echocardiogram measurements of PA dimension } \\
\hline Patients & 27 & & 14 & & \\
\hline RPA (mm), before NP & 27 & $4.7 \pm 0.7$ & 14 & $4.2 \pm 0.5$ & .01 \\
\hline RPA (mm), before BDG & 20 & $4.1 \pm 1$ & 12 & $4.4 \pm 1.4$ & .62 \\
\hline Change in RPA dimension & 17 & $-0.8 \pm 0.9$ & 12 & $0.1 \pm 1.5$ & .09 \\
\hline LPA (mm), before NP & 26 & $4.7 \pm 0.7$ & 14 & $4.3 \pm 0.7$ & .04 \\
\hline LPA $(\mathrm{mm})$, before BDG & 19 & $4.2 \pm 1$ & 12 & $4.5 \pm 1.5$ & .58 \\
\hline Change in LPA dimension & 15 & $-0.7 \pm 1.4$ & 12 & $0.2 \pm 1.8$ & .19 \\
\hline
\end{tabular}
PA; NP, Norwood procedure; $L P A$, left PA. *Number of patients and ratio represents number of interventions/number of catheterization procedures.

reduced in 1 , and severely reduced in 1 . In the right RV-PA conduit group, 8 patients had normal function, and 1 had moderately reduced function. No significant difference was found in the function between the left and right RV-PA groups at the baseline echocardiogram $(P=1)$. The median interval to the follow-up echocardiogram was 136 days (interquartile range, 113-155 days). On the preBDG echocardiogram, the left RV-PA group demonstrated normal function in 22 patients, mildly reduced in 2 , and moderately reduced in 1 . In the right RV-PA group, right ventricular function was normal in 10 patients, mildly reduced in 2 patients, and moderately reduced in 2 patients. No significant difference was found in ventricular function between the right and left RV-PA conduit on the pre-BDG echocardiogram $(P=.38)$.

Tricuspid valve regurgitation on the follow-up echocardiogram in the left RV-PPA group was as follows: none in 1 , trivial in 13 , mild in 5 , mild to moderate in 3 , moderate in 2 , and moderate to severe in 2 . Tricuspid valve regurgitation in the right RV-PA conduit group was as follows: trivial in 6 , mild in 6 , and moderate in 2 . No significant difference was found in tricuspid valve regurgitation between the 2 groups $(P=.53)$.

\section{DISCUSSION}

Advances in surgical technique and care for children with HLHS have improved overall survival. Despite these improvements, children with HLHS and variants associated with a single right ventricle are at high risk of morbidity and subsequent mortality within the first year of life. ${ }^{16,17}$ Controversy remains over which shunt to use, and most retrospective trials have demonstrated equivocal results, necessitating the need for a prospective trial. ${ }^{4,8,18-20}$ The
Single Ventricle Reconstruction trial reported improved survival to 12 months in children palliated with an RV-PA conduit. ${ }^{5}$ However, children palliated with an RV-PA conduit also had an increased need for unplanned cardiovascular interventions. Most of these interventions were the need for balloon dilation or stent placement in the shunt or branch PAs. ${ }^{5}$ The rate of catheterization interventions (shunt or PA) for the mBTS group from NP discharge to stage II discharge was $26 \%$ compared with $41 \%$ in the RV-PA conduit group. That study did not differentiate between shunt and PA interventions. This compares to $0 \%$ for the mBTS group and $15 \%$ for the RV-PA group in the present study from the $\mathrm{NP}$ to the BDG procedure. One potential explanation for the lack of catheter-based PA interventions in patients with the mBTS between the NP and BDG procedure is that access to the PAs for intervention is often difficult and might not be attempted. Although we did not include shunt interventions in the present study, the largest proportion of catheter-based PA interventions was performed between the BDG and Fontan procedures $(0 \%$ in the mBTS group and $32 \%$ in the RV-PA group). This was significantly greater than that reported by Ohye and colleagues ${ }^{5}$ in the Single Ventricle Reconstruction trial and similar to that reported by Mery and colleagues ${ }^{21}$ (36\% reintervention rate). Bautista-Hernandez and colleagues ${ }^{22}$ also reported a greater number of PA interventions in the RV-PA group after the Fontan procedure. Similar to our findings, they did not find a difference in the grade of tricuspid valve regurgitation between shunt types. ${ }^{22}$ The reasons the mBTS group did not require catheter-based $\mathrm{PA}$ interventions after the BDG procedure are unclear. The branch PA size decreased in both shunt types from the baseline echocardiogram to the follow-up echocardiogram. Consistent with previous 
investigations, the Qp/Qs ratio at the pre-BDG catheterization was increased in the mBTS group. ${ }^{1,2}$ Mroczek and colleagues $^{23}$ recently reported, in a study comparing the hemodynamics of the mBTS and RV-PA conduit using mathematical modeling, that the mBTS resulted in little change in blood pressure in the PAs with a slightly greater Qp/Qs ratio and greater right ventricular wall stress. In contrast, the RV-PA conduit model with the same cardiac output and systemic and pulmonary vascular resistance demonstrated pulsatile PA flow, with forward flow into the conduit occurring for $80 \%$ of the cardiac cycle and lower heart work. ${ }^{23}$ However, greater shear stress was present at the proximal and distal portions of the RV-PA conduit, which could lead to calcification, neointimal proliferation with subsequent shunt and PA stenosis, and clinical hypoxemia. ${ }^{23}$ This might be an explanation for the increased risk of PA interventions in the RV-PA conduit group. Our data demonstrated no difference in mortality between children palliated with an mBTS or an RV-PA conduit and were similar to the data reported by another retrospective study. ${ }^{3}$

The position of the RV-PA conduit to either the right or left of the neoaortic reconstruction has been reported by investigators to influence the growth of the PAs, especially the left PA. Rightward placement of the RV-PA conduit has been shown to provide a more balanced distribution of pulmonary blood flow and easier accessibility to the superior vena cava and right PA at the BDG procedure, theoretically decreasing the cardiopulmonary bypass time. ${ }^{9,10}$ The $\mathrm{Qp} / \mathrm{Qs}$ ratio was significantly greater if the RV-PA was placed to the right side of the neoaorta in our population, suggesting improved pulmonary blood flow. In addition, oxygen saturation by pulse oximetry at NP discharge was significantly greater in the right RV-PA conduit group. The difference in saturation between right- and left-sided placement $(83 \%$ vs $78 \%)$ was likely not clinically significant. The proportion of interventions after the NP was similar between the right and left RV-PA group; however, after the $\mathrm{BDG}$ procedure, the risk of $\mathrm{PA}$ interventions with the shunt to the right of the neoaorta was significantly greater than that with the shunt to the left. This suggests that rightward placement of the RV-PA conduit could be associated with either impaired PA growth or technical complications, resulting in acquired PA stenosis. The echocardiographic measurements of the PAs before any procedure demonstrated that those who ultimately underwent palliation with the RV-PA conduit to the right side of the neoaorta had significantly smaller left and right PAs compared with those who underwent palliation with the RV-PA conduit to the left side of the neoaorta. Although the growth of the PAs was seen in the right RV-PA conduit group at the follow-up echocardiogram for both the left and right PA, no growth was seen in the PAs when the RV-PA conduit was positioned to the left of the neoaorta. One can speculate then that the need for intervention is not determined by the lack of PA growth but rather a lower starting point in the right RV-PA group that then prompts intervention. Finally, although our study was designed to differentiate the need for catheter-based PA interventions with 2 different RV-PA conduit positions, other factors might play a role in the growth of the PAs, including the potential for PA compression as it passes behind the newly reconstructed neoaorta.

Cardiac transplantation had been used as the primary treatment of HLHS at our institution before the present study period. Beginning in 2001, the NP was increasingly used. During the study period, primary heart transplantation was performed for HLHS in 30 patients, most of which were performed early in the study period. Currently, staged palliation is the primary therapy offered at our institution, using the RV-PA conduit almost exclusively, unless anatomy prohibitive to shunt placement is present. Our operative mortality for the NP in the early era was high $(24 \%)$, with a reduction to $13 \%$ that has more recently declined to less than $8 \%$.

Although our study has provided insight into the differences in PA growth associated with shunt type and position, we acknowledge data-related limitations. The present study was a retrospective review at a single institution and was subject to the limitations associated with retrospective studies, including missing data. Some differences might be difficult to detect owing to a lack of power. Differences in PA growth could have been confounded by the size of the RV-PA conduit used, with the patients palliated with the 6-mm shunt having greater oxygen saturation at NP discharge and might be reflective of a greater $\mathrm{Qp} / \mathrm{Qs}$ ratio. Despite the lower oxygen saturation at discharge in patients palliated with a 5-mm shunt, the oxygen requirements were not different. The limitations resulting from the inherent subjectivity of the portions of echocardiographic data were minimized by the use of a single echocardiographer who was unaware of the original clinical reports and history of PA interventions. Measurement of the PAs off-line might have resulted in a small amount of measurement error. We sought to minimize this limitation by having a single cardiologist perform all catheterization measurements. Also, the procedures performed in during the study period included 4 different surgeons, using different surgical techniques that might have resulted in a prolongation of operative variables in the mBTS group and the potential for differential PA growth in the RV-PA group.

\section{CONCLUSIONS}

In the present single-institution review, the use of the RV-PA conduit or mBTS offers acceptable results and neither is associated with superior survival. However, the use of the RV-PA conduit is associated with increased PA interventions, in particular when the conduit is placed to the right of the neoaorta. However, there is some suggestion that overall PA growth is improved, as measured by the 
more equal distribution of pulmonary blood flow with an increase in branch PA dimensions. This improved growth might be confounded by the larger shunt size. Continued refinements in surgical technique could also obviate any significant differences and improve overall outcomes.

\section{References}

1. Pruetz JD, Badran S, Dorey F, Starnes VA, Lewis AB. Differential branch pulmonary artery growth after the Norwood procedure with right ventricle-pulmonary artery conduit versus modified Blalock-Taussig shunt in hypoplastic left heart syndrome. J Thorac Cardiovasc Surg. 2009;137:1342-8.

2. Rumball EM, McGuirk SP, Stumper O, Laker SJ, de Giovanni JV, Wright JG, et al. The RV-PA conduit stimulates better growth of the pulmonary arteries in hypoplastic left heart syndrome. Eur J Cardiothorac Surg. 2005;27:801-6.

3. Tabbutt S, Dominguez TE, Ravishankar C, Marino BS, Gruber PJ, Wernovsky G, et al. Outcomes after the stage I reconstruction comparing the right ventricular to pulmonary artery conduit with the modified Blalock Taussig shunt. Ann Thorac Surg. 2005;80:1582-90; discussion 90-1.

4. Ballweg JA, Dominguez TE, Ravishankar C, Kreutzer J, Marino BS, Bird GL, et al. A contemporary comparison of the effect of shunt type in hypoplastic left heart syndrome on the hemodynamics and outcome at stage 2 reconstruction. J Thorac Cardiovasc Surg. 2007;134:297-303.

5. Ohye RG, Sleeper LA, Mahony L, Newburger JW, Pearson GD, Lu M, et al. Comparison of shunt types in the Norwood procedure for single-ventricle lesions. N Engl J Med. 2010;362:1980-92.

6. Ohye RG, Ludomirsky A, Devaney EJ, Bove EL. Comparison of right ventricle to pulmonary artery conduit and modified Blalock-Taussig shunt hemodynamics after the Norwood operation. Ann Thorac Surg. 2004;78:1090-3.

7. Pizarro C, Malec E, Maher KO, Januszewska K, Gidding SS, Murdison KA, et al. Right ventricle to pulmonary artery conduit improves outcome after stage I Norwood for hypoplastic left heart syndrome. Circulation. 2003;108(suppl 1): II155-60.

8. Reemtsen BL, Pike NA, Starnes VA. Stage I palliation for hypoplastic left heart syndrome: Norwood versus Sano modification. Curr Opin Cardiol. 2007;22: 60-5.

9. Barron DJ, Brooks A, Stickley J, Woolley SM, Stumper O, Jones TJ, et al. The Norwood procedure using a right ventricle-pulmonary artery conduit: comparison of the right-sided versus left-sided conduit position. $J$ Thorac Cardiovasc Surg. 2009;138:528-37.

10. Kolcz J, Skladzien T, Kordon Z, Rudzinski A, Skalski J. Impact of right ventriclepulmonary artery conduit placement on the pulmonary arteries development after the Norwood procedure in hypoplastic left heart syndrome. Eur J Cardiothorac Surg. 2012;42:218-23.

11. Jacobs JP, Mavroudis C, Jacobs ML, Maruszewski B, Tchervenkov CI, LacourGayet FG, et al. What is operative mortality? Defining death in a surgical registry database: a report of the STS Congenital Database Taskforce and the Joint EACTS-STS Congenital Database Committee. Ann Thorac Surg. 2006;81: 1937-41.

12. Zoghbi WA, Enriquez-Sarano M, Foster E, Grayburn PA, Kraft CD, Levine RA, et al. Recommendations for evaluation of the severity of native valvular regurgitation with two-dimensional and Doppler echocardiography. J Am Soc Echocardiogr. 2003;16:777-802.

13. Nakata S, Imai Y, Takanashi Y, Kurosawa H, Tezuka K, Nakazawa M, et al. A new method for the quantitative standardization of cross-sectional areas of the pulmonary arteries in congenital heart diseases with decreased pulmonary blood flow. J Thorac Cardiovasc Surg. 1984;88:610-9.

14. Piehler JM, Danielson GK, McGoon DC, Wallace RB, Fulton RE, Mair DD. Management of pulmonary atresia with ventricular septal defect and hypoplastic pulmonary arteries by right ventricular outflow construction. $J$ Thorac Cardiovasc Surg. 1980;80:552-67.

15. Harris PA, Taylor R, Thielke R, Payne J, Gonzalez N, Conde JG. Research electronic data capture (REDCap) - a metadata-driven methodology and workflow process for providing translational research informatics support. J Biomed Informat. 2009;42:377-81.

16. Hehir DA, Dominguez TE, Ballweg JA, Ravishankar C, Marino BS, Bird GL, et al. Risk factors for interstage death after stage 1 reconstruction of hypoplastic left heart syndrome and variants. J Thorac Cardiovasc Surg. 2008;136:94-9, 9.e1-3.

17. Stasik CN, Gelehrter S, Goldberg CS, Bove EL, Devaney EJ, Ohye RG. Current outcomes and risk factors for the Norwood procedure. J Thorac Cardiovasc Surg. 2006;131:412-7.

18. Edwards L, Morris KP, Siddiqui A, Harrington D, Barron D, Brawn W. Norwood procedure for hypoplastic left heart syndrome: BT shunt or RV-PA conduit? Arch Dis Child Fetal Neonatal Ed. 2007;92:F210-4.

19. Wernovsky G, Ghanayem N, Ohye RG, Bacha EA, Jacobs JP, Gaynor JW, et al. Hypoplastic left heart syndrome: consensus and controversies in 2007. Cardiol Young. 2007; 17(suppl 2):75-86.

20. Lai L, Laussen PC, Cua CL, Wessel DL, Costello JM, del Nido PJ, et al. Outcomes after bidirectional Glenn operation: Blalock-Taussig shunt versus right ventricle-to-pulmonary artery conduit. Ann Thorac Surg. 2007;83:1768-73.

21. Mery CM, Lapar DJ, Seckeler MD, Chamberlain RS, Gangemi JJ, Kron IL, et al. Pulmonary artery and conduit reintervention rates after Norwood using a right ventricle to pulmonary artery conduit. Ann Thorac Surg. 2011;92:1483-9; discussion 9.

22. Bautista-Hernandez V, Scheurer M, Thiagarajan R, Salvin J, Pigula FA, Emani S, et al. Right ventricle and tricuspid valve function at midterm after the Fontan operation for hypoplastic left heart syndrome: impact of shunt type. Pediatr Cardiol. 2011;32:160-6.

23. Mroczek T, Malota Z, Wojcik E, Nawrat Z, Skalski J. Norwood with right ventricle-to-pulmonary artery conduit is more effective than Norwood with Blalock-Taussig shunt for hypoplastic left heart syndrome: mathematic modeling of hemodynamics. Eur J Cardiothorac Surg. 2011;40:1412-7; discussion 7-8. 